\title{
EFFECTIVENESS OF DARK CHOCOLATE AND GINGER ON PAIN REDUCTION SCALE IN ADOLESCENT DYSMENORHEA
}

\author{
Rizky Amelia ${ }^{1)}$ Sandy Isna Maharani ${ }^{2)}$ \\ rizkyamelia81@yahoo.com
}

\begin{abstract}
Pain during menstruation (dysmenorrhea) are the most common complaints in women. To reduce pain during menstruation (primary dysmenorrhea) there are several ways including the use of drugs - drugs analgesic, anti-inflammatory, the use of herbal remedies, relaxation techniques, exercise period, as well as massage therapy.

The study aims to determine the effectiveness of consumption of dark chocolate and ginger to reduce the scale of pain in primary dysmenorrhea. This type of research is a Quasi experiment, the type of study design pretest - posttest with control group. Respondents in this experiment is a student hostel Bhakti Husada Polytechnic of Semarang Kemenkes a level 1 each - each group of 17 people for giving dark chocolate, Ginger and Control. The instruments used are NRS (Numerik Rating Scale). Data was analyzed by univariate and bivariate.

Obtained results showed $p$-value of $0.029(\alpha<0.05)$ showed that there were significant differences between awarding dark chocolate and Ginger to decrease menstrual pain compared to the control group. Dark chocolate and ginger can be a complementary therapy to cope with menstrual pain.
\end{abstract}

Keywords: the level of pain of dysmenorrhea, dark chocolate, ginger

1),2) Lecture of Diploma Programme Midwifery Semarang

Dismenore adalah rasa sakit yang menyertai menstruasi sehingga dapat menimbulkan gangguan pekerjaan sehari-hari. Rasa sakit yang menyerupai kejang ini terasa diperut bagian bawah, biasanya dimulai 24 jam sebelum haid datang dan berlangsung sampai 12 jam pertama dari masa haid, setelah itu semua rasa tidak enak tadi hilang. (Manuaba dkk, 2008).

Prevalensi nyeri menstruasi (dismenorea) primer dilaporkan bervariasi antara $50 \% \quad-\quad 90 \%$. Dismenore dapat dialami lebih dari setengah wanita yang sedang menstruasi, dan prevalensinya sangat bervariasi. Berdasarkan data dari berbagai negara, angka kejadian dismenore di dunia cukup tinggi. Diperkirakan $50 \%$ dari seluruh wanita di dunia menderita dismenore dalam sebuah siklus menstruasi. Pasien melaporkan nyeri saat haid, dimana sebanyak $12 \%$ dismenore sudah parah, 37\% dismenore sedang, dan 49\% dismenore masih ringan (Calis, 2011). Menurut Cakir $M$ et al (2007) dalam penelitiannya menemukan bahwa dismenore merupakan gangguan menstruasi dengan prevalensi terbesar $(89,5 \%)$. Penelitian lain didapatkan prevalensi dismenore bervariasi antara 15,8-89,5\%, dengan 
prevalensi tertinggi pada remaja (Calis dkk, 2009). Penanganan dismenore bisa dilakukan secara farmakologi yaitu dengan pemberian obat-obatan analgesik golongan non steroidal anti inflamatory drugs (NSAID) seperti ibuprofen, asam mefenamat, aspirin.(Wilmana \& Gan,2007). Sebesar $38 \%$ wanita biasanya menggunakan terapi farmakologi untuk menangani dismenorea.(Mei Ling et al, 2013 dalam Awed Howida,2013). Sedangkan secara non farmakologi dapat melalui distraksi, relaksasi, imajinasi terbimbing, kompres hangat atau dingin (Potter \& Perry, 2005). Beberapa penelitian juga menyebutkan hubungan beberapa zat gizi dengan penurunan tingkat dismenore. Sebuah buku yang ditulis oleh Devi (2012) zat gizi yang dapat membantu meringankan dismenore adalah kalsium, magnesium serta vitamin $A$, E, B6, dan C.

Salah satu terapi non farmakologis dari segi gizi yang dapat dijadikan alternatif untuk mengatasi rasa nyeri pada saat menstruasi yaitu coklat hitam. Dark Chocolate atau cokelat hitam kaya akan kalsium, kalium, natrium, magnesium serta vitamin $A$, B1, C, D, dan E, Magnesium berguna untuk merelaksasikan otot dan dapat memberikan rasa rileks yang dapat mengendalikan suasana hati yang murung (Hill, 2002). Magnesium berfungsi memperbesar pembuluh darah sehingga mencegah kejang otot dan dinding pembuluh darah. Magnesium berfungsi untuk meringankan dismenore atau rasa nyeri saat haid (Devi, 2012).
Terapi non farmakologis lain yang dapat digunakan untuk mengurangi dismenorea adalah dengan pengobatan herbal, pemberian suplemen, perawatan medis, hipnoterapi dan akupuntur. Terapi ramuan herbal dapat dilakukan dengan cara menggunakan obat tradisional yang berasal dari bahan - bahan tanaman. Beberapa bahan tanaman dipercaya dapat digunakan untuk mengurangi nyeri yaitu kayu manis, kedelai, cengkeh, kunyit, jahe (ginger) dan herbal cina. (Anurogo dan Wulandari, 2011). Beberapa studi menyebutkan bahwa jahe (ginger) merupakan antiinflamasi dan anti karsinogenik yang efektif. (Ali 2008). Zingiber officinale adalah nama latin dari jahe. Kandungan yang terdapat dalam jahe antara lain gingerol, gingerdiol, gingerdione, beta caroten, capsaicin, caffeic acid dan curcumin. Beberapa studi menyebutkan bahwa jahe mempunyai efek yang bermanfaat terhadap pencegahan kanker, mual dan muntah saat kehamilan, mual muntah pada pasien kemoterapi, dan mual muntah setelah tindakan operasi. Jahe dengan fungsi anti inflamasi menghambat produksi prostaglandin. Jahe merupakan terapi yang aman untuk menghilangkan nyeri pada wanita dengan dismenorea primer pada awal menstruasi sampai dengan hari ke 3 menstruasi.(Rahmana et all 2012).

\section{METODE PENELITIAN}

Penelitian ini menggunakan metode Quasi Experimental Design dengan pendekatan Pretest-Posttest Control Group Design. Metode Quasi Experimental adalah metode penelitian 
eksperimen dengan menggunakan kelompok kontrol, tetapi tidak sepenuhnya untuk mengontrol variabel - variabel luar yang mempengaruhi penelitian. Rancangan Quasi Experimental minimal memenuhi satu dari tiga syarat rancangan true experiment yaitu: sampel diambil secara acak, ada kelompok kontrol, dan adanya intervensi. Rancangan Pretest-Posttest Control Group Design dilakukan dengan menilai sebelum dan setelah perlakukan pada kelompok kontrol dan intervensi.

Subyek penelitian ini adalah seluruh remaja putri di kota Semarang. Populasi terjangkau adalah populasi yang dibatasi karakteristik klinis, geografis, tempat dan waktu. Populasi terjangkau penelitian ini adalah semua mahasiswa tingkat I yang tinggal di asrama Bakti Husada Poltekkes Kemenkes Semarang pada tahun akademik 2016/2017. Teknik pengambilan sampel dalam penelitian ini adalah consecutive sampling. Pada consecutive sampling, semua subjek yang datang dan memenuhi kriteria pemilihan dimasukkan dalam penelitian sampai jumlah subjek yang diperlukan terpenuhi. Consecutive sampling ini merupakan jenis nonprobability sampling yang paling baik, dan sering merupakan cara termudah. Sebagian besar penelitian klinis (termasuk uji klinis) menggunakan teknik ini untuk pemilihan subjeknya. (Sastroasmoro, 2008). jumlah sampel yang didapatkan sejumlah 17 orang untuk masing - masing kelompok. Sehingga total jumlah sampel dalam penelitian ini adalah 51 orang untuk 3 kelompok.
Peneliti mengobservasi dan mendeskripsikan skala nyeri dismenorea pada remaja putri kelompok $A$ yaitu sebelum dan sesudah pemberian coklat hitam $40 \mathrm{gr}$ 1 kali sehari 3 hari sebelum dan 3 hari selama menstruasi, kelompok B yaitu sebelum dan sesudah pemberian jahe bubuk satu sendok makan yang dilarutkan dalam $200 \mathrm{cc}$ air hangat 3 kali sehari pada 3 hari sebelum dan 3 hari selama menstruasi dan pada kelompok $\mathrm{C}$ sebelum dan sesudah tanpa perlakuan. Analisis data univariate menggunakan distribusi frekuensi dan analisis bivariate menggunakan repeated measure anova.

HASIL PENELITIAN

a. Tingkat Nyeri Dismenore Remaja Putri Sebelum Pemberian Coklat Hitam

Tabel 1 Distribusi Frekuensi Tingkat Nyeri Dismenore Remaja Putri Sebelum Pemberian Coklat Hitam

\begin{tabular}{ccc}
\hline $\begin{array}{c}\text { Tingkat } \\
\text { Nyeri }\end{array}$ & Frekuensi & $\%$ \\
\hline 6 & 3 & 17,6 \\
\hline 7 & 7 & 41,2 \\
\hline 8 & 5 & 29,4 \\
\hline 9 & 2 & 11,8 \\
\hline Total & 17 & 100 \\
\hline Mean & Median 7,00 & \\
7,35 & & terlihat
\end{tabular}

bahwa tingkat nyeri Dismenore pada remaja putri sebelum pemberian coklat hitam paling banyak dalam skala 7 yaitu sebanyak 7 responden $(41,2 \%)$ dan skala 8 yaitu sebanyak 5 responden $(29,4 \%)$.

Nyeri yang dirasakan responden paling banyak berada di skala 7 dan 8 dengan pengukuran skala nyeri NRS. Gejala yang dirasakan adalah terganggunya aktivitas sehari-sehari 
sehingga responden membutuhkan terapi baik berupa obat jenis analgesic maupun minuman-minuman yang dipercaya dapat digunakan sebagai obat herbal dalam mengatasi nyeri menstruasinya.

Penggunaan analgesic memang sering digunakan oleh wanita yang mengalami nyeri menstruasi karena selain mudah didapatkan, efeknya juga cukup cepat untuk meredakan rasa nyerinya. Namun analgesik hanyalah bersifat simtomatik hanya membantu mengatasi nyeri dan gejala lainnya serta bersifat sementara saja. Analgesik tidak mampu meredakan gejala psikis ataupun emosional yang disebabkan oleh nyeri menstruasi. Begitu juga dengan obat herbal yang diminum wanita saat mengalami nyeri menstruasi di hari pertama sampai ketiga. Saat terjadi gangguan aktivitas, wanita memiliki mengkonsumsi makanan ataupun minuman yang dia percayai dapat menghilangkan nyeri saat menstruasi. Namun karena responden berupa remaja yang memiliki banyak kegiatan dan aktivitas, mereka cenderung tidak mengenal konsumsi coklat hitam maupun jahe karena apa yang mereka konsumsi adalah sesuatu yang dikenal oleh banyak orang, kebiasaan, sesuai dengan pengalaman dan cerita dari orang terdekat dalam hal ini adalah teman, sahabat maupun peer groupnya.

b. Tingkat Nyeri Dismenore Remaja Putri Sesudah Pemberian Coklat Hitam

Tabel 2 Distribusi Frekuensi Tingkat Nyeri Dismenore Remaja Putri Sesudah Pemberian Coklat Hitam

\begin{tabular}{rcc}
\hline $\begin{array}{c}\text { Tingkat } \\
\text { Nyeri }\end{array}$ & Frekuensi & $\%$ \\
\hline 1 & 2 & 11,8 \\
\hline 2 & 5 & 29,4 \\
\hline 3 & 6 & 35,3 \\
\hline 4 & 2 & 11,8 \\
\hline 5 & 1 & 5,9 \\
\hline 6 & 1 & 5,9 \\
\hline Total & 17 & 100 \\
\hline Me & Median 3,00 \\
\hline
\end{tabular}

an 2,88

Berdasarkan tabel 2 terlihat bahwa tingkat nyeri Dismenore pada remaja putri sesudah pemberian coklat hitam paling banyak dalam skala 3 yaitu sebanyak 6 responden $(35,3 \%)$ dan skala 2 yaitu sebanyak 5 responden $(29,4 \%)$.

Responden yang mengalami nyeri menstruasi mengalami penurunan kadar nyeri dilihat dari hasil pemeriksaan skor nyeri dari yang semula sebagian besar berada di skala 7 dan 8 setelah mendapatkan terapi coklat hitam sebanyak 40 gram selama 3 hari berturut-turut. Hasil skala nyeri hanya 1 sampai dengan 6 dengan skala nyeri 5 dan 6 masingmasing 1 responden. Itu menunjukkan penurunan yang cukup bermakna.

Faktor nutrisi memang memiliki pengaruh dalam penurunan skala nyeri menstruasi. Sesuai dengan hasil penelitian Wenny (2015), menyatakan bahwa Defisiensi dari zat gizi mikro, salah satunya magnesium berhubungan dengan gejala neuropsikiatri yang sering terjadi seperti gangguan mood dan gejala fisik remaja yang mengalami awal menstruasi. Dalam coklat hitam yang kaya kalsium dan magnesium alami dapat memberikan efek langsung dalam merelaksasi otot polos dalam dinding rahim saat menstruasi baru saja terjadi. Sehingga nyeri yang 
dirasakan remaja berkurang, dan efek menenangkan dari zat coklat hitam yang lain berupa natural endorphin sehingga menghilangkan gejala psikis lainnya.

\section{c. Tingkat Nyeri Dismenore Remaja Putri Sebelum Pemberian Jahe}

Tabel 3 Distribusi Frekuensi Tingkat Nyeri Dismenore Remaja Putri Sebelum Pemberian Jahe

\begin{tabular}{ccc}
\hline $\begin{array}{c}\text { Tingkat } \\
\text { Nyeri }\end{array}$ & Frekuensi & $\%$ \\
\hline 5 & 3 & 17,6 \\
\hline 6 & 6 & 35,3 \\
\hline 7 & 3 & 17,6 \\
\hline 8 & 5 & 29,4 \\
\hline Total & 17 & 100 \\
\hline Mean & Median & \\
6,59 & 6,00 & \\
\hline
\end{tabular}

Berdasarkan

tabel 5.3 terlihat bahwa tingkat nyeri Dismenore pada remaja putri sebelum pemberian jahe paling banyak dalam skala 6 yaitu sebanyak 6 responden $(35,3 \%)$ dan skala 8 yaitu sebanyak 5 responden $(27,4 \%)$.

Penggunaan analgesic memang sering digunakan oleh wanita yang mengalami nyeri menstruasi karena selain mudah didapatkan, efeknya juga cukup cepat untuk meredakan rasa nyerinya. Namun analgesik hanyalah bersifat simtomatik hanya membantu mengatasi nyeri dan gejala lainnya serta bersifat sementara saja. Analgesik tidak mampu meredakan gejala psikis ataupun emosional yang disebabkan oleh nyeri menstruasi. Begitu juga dengan obat herbal yang diminum wanita saat mengalami nyeri menstruasi di hari pertama sampai ketiga. Saat terjadi gangguan aktivitas, wanita memiliki mengkonsumsi makanan ataupun minuman yang dia percayai dapat menghilangkan nyeri saat menstruasi. Namun karena responden berupa remaja yang memiliki banyak kegiatan dan aktivitas, mereka cenderung tidak mengenal konsumsi coklat hitam maupun jahe karena apa yang mereka konsumsi adalah sesuatu yang dikenal oleh banyak orang, kebiasaan, sesuai dengan pengalaman dan cerita dari orang terdekat dalam hal ini adalah teman, sahabat maupun peer groupnya.

\section{d. Tingkat Nyeri Dismenore Remaja} Putri Sesudah Pemberian Jahe

Tabel 4 Distribusi Frekuensi Tingkat Nyeri Dismenore Remaja Putri Sesudah Pemberian Jahe

\begin{tabular}{ccc}
\hline $\begin{array}{c}\text { Tingkat } \\
\text { Nyeri }\end{array}$ & $\begin{array}{c}\text { Frekuens } \\
\text { i }\end{array}$ & $\%$ \\
\hline 1 & 5 & 27,4 \\
\hline 2 & 5 & 27,4 \\
\hline 3 & 4 & 23,5 \\
\hline 4 & 2 & 11,8 \\
\hline 5 & 1 & 5,9 \\
\hline Total & 17 & 100 \\
\hline Mean & Median & \\
2,35 & 2,00 & \\
\hline
\end{tabular}

Berdasarkan tabel 4 terlihat bahwa tingkat nyeri Dismenore pada remaja putri sesudah pemberian jahe paling banyak dalam skala 1 dan 2 yaitu masing - masing sebanyak 5 responden $(27,4 \%)$

Setelah diberikan jahe selama 3 hari, hasil dari pengukuran nyeri menstruasi remaja mengalami penurunan. Terdapat hanya 1 orang responden yang masih merasakan nyeri saat menstruasi skla 5. Namun selebihnya sudah tidak ditemukan lagi. Sebelum 
mendapatkan terapi jahe, responden menyatakan nyeri menstruasi hingga ke gejala ketidaknyamanan yang lain seperti perut mual, kembung dan kepala pusing sehingga ada beberapa responden yang awalnya membutuhkan analgesik sebagai terapi kini tidak meminum lagi setelah diterapi menggunakan jahe.

Sesuai dengan apa yang telah disampaikan oleh Wijayakusuma (2008), bahwa Jahe bermanfaat melancarkan sirkulasi darah, antradang, karminatif, peluruh keringat, dan peluruh dahak. Untuk mengatasi asma, batuk, bronkhitis, sakit kepala, influenza, sinusitis, rematik sendi, perut kembang, masuk angin, mual, dan nyeri haid.

\section{e. Tingkat Nyeri Dismenore Remaja} Putri Pengukuran Bulan Pertama Pada Kelompok Kontrol

Tabel 5 Distribusi Frekuensi Tingkat Nyeri Dismenore Remaja Putri Pengukuran Bulan Pertama Pada Kelompok Kontrol

\begin{tabular}{ccc}
\hline $\begin{array}{c}\text { Tingkat } \\
\text { Nyeri }\end{array}$ & Frekuensi & $\%$ \\
\hline 5 & 5 & 27,4 \\
\hline 6 & 7 & 41,2 \\
\hline 7 & 4 & 23,5 \\
\hline 8 & 1 & 5,9 \\
\hline Total & 17 & 100 \\
\hline Mean 6,06 & Median 6,00 & \\
\hline
\end{tabular}

Berdasarkan tabel 5 terlihat bahwa tingkat nyeri Dismenore pada remaja putri pada pengukuran bulan pertama paling banyak dalam skala 6 yaitu sebanyak 7 responden $(41,2 \%)$.

Pada responden kelompok kontrol saat dilakukan pemeriksaan di bulan pertama, satu orang menyatakan nyeri menstruasi berat. Responden menyatakan menggunakan analgesik dan mengkonsumsi air kunyit serta istirahat jika nyeri hebat datang saat hari pertama menstruasi. Mereka menyatakan bahwa nyeri saat menstruasi menyebabkan remaja tidak dapat beraktivitas dan enggan untuk belajar karena tidak dapat berkonsentrasi. Dengan permasalahan asrama yang tidak sering terjadi dan mahasiswa belajar untuk beradaptasi tinggal di lingkungan baru menambah rasa tidak nyaman saat menstruasi.

\section{f. Tingkat Nyeri Dismenore Remaja Putri Pengukuran Bulan Kedua Pada Kelompok Kontrol}

Tabel 6 Distribusi Frekuensi Tingkat Nyeri Dismenore Remaja Putri Pengukuran Bulan Kedua Pada Kelompok Kontrol

\begin{tabular}{ccc}
\hline $\begin{array}{c}\text { Tingkat } \\
\text { Nyeri }\end{array}$ & Frekuensi & $\%$ \\
\hline 2 & 1 & 5,9 \\
\hline 3 & 2 & 11,8 \\
\hline 4 & 4 & 23,5 \\
\hline 5 & 7 & 41,2 \\
\hline 6 & 3 & 17,6 \\
\hline Total & 17 & 100 \\
\hline Mean 4,53 & Median \\
& 5,00 & \\
\hline
\end{tabular}

Berdasarkan tabel 6 terlihat bahwa tingkat nyeri Dismenore pada remaja putri pada pengukuran bulan kedua paling banyak dalam skala 5 yaitu sebanyak 7 responden $(41,2 \%)$,

Setelah dilakukan penilaian bulan berikutnya, responden kelompok kontrol tenyata mengalami perubahan tingkat nyeri walaupun tidak mendapatkan terapi coklat hitam maupun jahe saat menstruasi. Responden mendapatkan susu kental manis berwarna putih sebagai kontrol 
yang komposisinya tidak mengandung banyak zat yang dapat menredakan nyeri menstruasi seperti zat gizi yang berada pada coklat dan jahe.

Penurunan skala nyeri disebabkan karena beberapa responden mengatasinya dengan beraktivitas dan tidak merasa bahwa nyeri menstruasi adalah sebuah hambatan dalam melakukan aktivitas harian. Adapun reponden pada kelompok kontrol yang masih merasakan nyeri di skala 6 merasa bahwa pada saat menstruasi nyeri yang mereka rasakan tidak dapat berkurang secara signifikan walaupun mendapat susu kental manis warna putih dari peneliti.

Nyeri yang dirasakan responden merupakan kejadian fisiologis pada wanita terutama saat menstruasi terjadi setiap bulan. Rasa nyeri di perut bagian bawah selama menstruasi berlangsung dengan fungsi ovarium dan pemeriksaan pelvic normal. Biasanya akan hilang dengan sendirinya dan tidak memerlukan tindakan medis.

\section{g. Perbedaan Efektivitas Pemberian Coklat Hitam dan Jahe Terhadap Penurunan Tingkat Nyeri Dismenorea Pada Remaja Putri.}

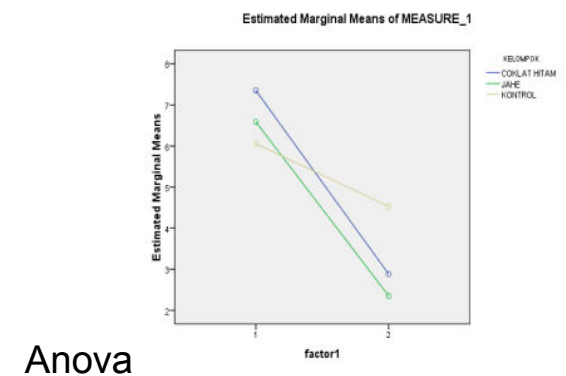

Diketahui bahwa $p$ value 0,029 ( $\alpha$ $<0,05)$ yang artinya ada perbedaan yang bermakna, tingkat nyeri dismenorea pada remaja putri sebelum dan sesudah pemberian intrevensi berupa Coklat Hitam dan Jahe dibandingkan dengan kelompok kontrol.

Terdapat perbedaan bermakna antara tingkatan nyeri menstruasi pada remaja sebelum dan sesudah pemberian intervensi berupa coklat hitam dan jahe dibandingkan dengan kelompok kontrol ( $p$ value 0,029 ). Itu artinya bahwa kelompok responden yang menerima terapi berupa coklat hitam dan jahe lebih mengalami penurunan tingkat nyeri menstruasi dibandingkan kelompok kontrol yang tidak diberikan keduanya. Itu terbukti bahwa susu kental manis warna putih kurang memberikan pengaruh yang signifikan terhadap penurunan nyeri menstruasi.

Uji laboratorium memperlihatkan bahwa ekstrak jahe dalam air panas menghambat aktivitas lipoksigenase dan siklooksigenase sehingga menurunkan kadar prostaglandin dan leukotriena (mediator inflamasi). Menetralkan efek merusak yang disebabkan oleh radikal bebas. Sehingga dapat digunakan oleh wanita yang memiliki keluhan setiap datang bulanannya. Rasa jahe yang hangat juga dapat memberikan efek nyaman pada pencernaan yang mengalami ketidaknyamanan saat menstruasi di hari pertama sampai ketiga.

Jahe merupakan terapi yang aman untuk menghilangkan nyeri pada wanita dengan dismenorea primer pada awal menstruasi sampai dengan hari ke 3 menstruasi (Rahmana et all 2012). Sedangkan coklat hitam dengan kadar yang tinggi dapat menghasilkan magnesium dan kalsium alami pada tubuh sehingga dapat 
membuat kontraksi uterus saat menstruasi menjadi relax dan mencegah terjadinya inflamasi pada rahim.

\section{SIMPULAN}

1. Responden yang mengalami nyeri menstruasi mengalami penurunan kadar nyeri (skala 6 hanya 1 orang) dilihat dari hasil pemeriksaan skor nyeri dari yang semula sebagian besar berada di skala 8 dan 9 setelah mendapatkan terapi coklat hitam sebanyak 40 gram selama 3 hari menurun.

2. Setelah diberikan jahe selama 3 hari, hasil dari pengukuran nyeri menstruasi remaja mengalami penurunan.

3. Pada responden kelompok kontrol saat dilakukan pemeriksaan di bulan pertama, sejumlah 5 orang menyatakan nyeri berat dan 7 orang mengalami nyeri menstruasi sedang. Setelah dilakukan penilaian bulan berikutnya, responden kelompok kontrol tenyata mengalami perubahan tingkat nyeri walaupun tidak mendapatkan terapi coklat hitam maupun jahe saat menstruasi. Itu dikarenakan responden memenuhi kebutuhan gizinya dengan susu kental manis warna putih saat mengalami menstruasi.

4. Responden yang mengkonsumsi coklat hitam mengalami penurunan tingkat nyeri dismenore lebih signifikan dibandingkan kelompok kontrol.

5. Responden yang diberikan terapi berupa jahe mengalami penurunan nyeri menstruasi yang signifikan dibandingkan kelompok kontrol.

6. Didapatkan $p$-value sebesar 0,029 $(\alpha<0,05)$ menunjukkan bahwa terdapat perbedaan bermakna antara pemberian Coklat Hitam dan Jahe terhadap penurunan nyeri mentruasi terhadap responden kontrol.

\section{SARAN}

1. Bagi Masyarakat

Coklat hitam dan jahe dapat menjadi terapi komplementer sebagai alternatif pemecahan masalah pada kesehatan reproduksi remaja yaitu mengatasi nyeri menstruasi setiap bulan sehingga tidak lagi mengkonsumsi obat-obatan berbahan kimia lain yang mungkin tidak terjamin komposisi dan manfaatnya.

2. Bagi Ilmu Pengetahuan

Mampu menjadikan ilmu baru bagi kesehatan khususnya dibidang kebidanan kesehatan reproduksi remaja dalam upaya mengatasi, mengobati dan menurunkan tingkat nyeri menstruasi kepada remaja dan wanita.

\section{Bagi Peneliti}

Menjadikan sumber referensi baru dan pengetahuan baru sehingga peneliti berikutnya tertarik untuk mengembangkan penelitian ini dengan mempertimbangkan jumlah sampel, vaiabel dan populasi yang lebih bervariatif

\section{DAFTAR PUSTAKA}

Anurogo, W. 2011. Cara Jitu Mengatasi Nyeri Haid. Yogyakarta : C. V ANDI OFFSET.

Calis,K.A.(2009). Dysmenorrhea. Terdapat pada: http://repository.usu.ac.id/bitstream/12 345 6789/31657/4/Chapter\%20ll.pdf. Diakses pada tanggal 5 Februari 2016. 
Devi,N. (2012). Gizi saat sindrom menstruasi. Jakarta : PT Bhuana IImu Populer Kelompok Gramedia.

Dewi, Ocha Septia. 2013. Herbal Taklukan Ragam Penyakit. Jogjakarta : Flash Books

Manuaba, I.A.C., I.B.G.F., \& I.B.G. (2009). Memahami Kesehatan Reproduksi Wanita.

Edisi 2. Jakarta: EGC

Rahnama $\mathrm{P}$, Montazeri Ali, Huseini HF, Kianbakhi S, Naser M (2012). Effect of Zingiber officinale R.Rhizomes (ginger) on pain relief in Primary dysmenorrhea : a placebo randomized trial. BMC. Complementary and Alternative Med. 12(92) : 1 - 7 doi : 10.1186/14726882-12-92

Ramadhan. 2013. Aneka Manfaat Ampuh Rimpang Jahe Untuk Pengobatan. Yogyakarta: Diandra Pustaka Indonesia.
Rismunandar, 1988. Rempahrempah Komoditi Ekspor Indonesia. Bandung : CV Sinar Baru

Sastroasmoro, Sudigdo dan Ismail, Sofyan.2008. Dasar - dasar Metodologi Penelitian Klinis. Edisi ke 3. Jakarta. Sagung Seto.

Wilmana, F.K., \& Gan, S. (2007). Analgesik-antipiretik analgesik antiinflamasi nonsteroid dan obat gangguan sendi lainnya. Terdapat pada:

http://repository.usu.ac.id/bitstream/12 345

\section{9/31671/4/Chapter\%20II.pdf} Diakses pada tanggal 5 Februari 2016.

Yeh Ml, Hung YL, Chen HH, Wang Yj (2012). Auricular Acupressure for Pain relief in Adolescent with Dysmenorrhea : A Placebo Controlled Study. J. Altern. Complement Med.2012 : Nov. Pp.6 